- patients. Having read about Steptoe's pioneering work on laparoscopy — the placement of a fibre-optic endoscope into the abdomen to view internal organs - in his small hospital in northern England, Edwards picked up the phone. Steptoe was already using the method to withdraw fluid from the reproductive tract and agreed that he could also use it to extract eggs. Working as equal partners, the pair set out their own ethical guidelines, agreeing to stop if patients or children were endangered, but not in deference to what Edwards called "vague religious or political reasons".

The UK Medical Research Council refused to fund their work, believing it could lead to babies with severe abnormalities, and disapproving of the pair's high profile in the media (M. H. Johnson et al. Hum. Reprod. 25, 2157-2174; 2010).

Johnson recalls the "strange atmosphere" in the 1960s and 1970s, when the prospect of overpopulation seemed to be a bigger societal concern than infertility. "There was no awareness then of the personal pain of infertility," he says. "I remember eminent Cambridge scientists would tell us that our $\mathrm{PhD}$ supervisor was off his rocker." He also recalls Max Perutz and James Watson, both Nobel laureates at Cambridge, telling him it was irresponsible to interfere with the beginning of life. "Often people refused to speak to us in the tea room because they disapproved of what we were doing." Johnson stuck by Edwards though, finding him "inspirational and visionary".

The technique has not only benefitted infertile couples - it can also help parents to avoid passing on serious inherited diseases such as cystic fibrosis or Huntington's disease to their children, by selecting embryos that are free of dangerous mutations for implantation.

In addition, it has enabled the field of human embryonic stem-cell research. Reproductive biologist Outi Hovatta of the Karolinska Institute's IVF clinic in Stockholm, where new human embryonic stem-cell lines are derived from spare embryos, says that Edwards was the first, in 1984, to publicly discuss the benefits of such cells to medical research, and the ethical dilemmas that would inevitably accompany them. He was equally prescient on the need for oversight of his powerful technique, advocating in 1971 that a legal authority should be established to control IVF. The UK Human Fertilisation and Embryology Authority was founded 20 years later.

\title{
Graphene speeds pair to Stockholm win
}

\section{Research on carbon sheets scores Nobel Prize in Physics.}

\section{BY GEOFF BRUMFIEL}

S heets of carbon with the potential to revolutionize electronics and materials science have bagged this year's Nobel Prize in Physics. Andre Geim and Konstantin Novoselov at the University of Manchester, UK, have been awarded the prize for their work on graphene, a one-atom-thick hexagonal mesh of carbon atoms that has become physicists' material du jour.

Geim and Novoselov reported the first freestanding graphene samples in 2004, having used little more than adhesive tape to create the material. Their team stuck the tape to a piece of graphite, peeled off flakes of carbon and then separated graphene from the rest of the flakes. Placing the graphene onto a silicon substrate, the researchers showed that it is a good electrical conductor ${ }^{1}$.

Graphene's relatively recent rise to prominence makes it an unusual candidate for a Nobel, and marks the shortest lag-time between experiment and award since Johannes Georg Bednorz and Karl Alexander Müller won the physics prize for their discovery of high-temperature superconductivity in 1987, 18 months after their findings were published.

"I think very few doubted that there would be a Nobel prize," says Andrea Ferrari, an electrical engineer at the University of Cambridge, UK, who researches graphene applications. But, he adds, "I was surprised that it came so early." The award caught even Geim off guard. "When I got the telephone call, I thought, 'oh shit!", he told reporters at a press conference shortly after the announcement. "The second thought that came to my mind was, 'Oh dear, I will not win many more prizes."

Graphene's win may be down to the astonishing speed at which the field has developed. Almost immediately after its

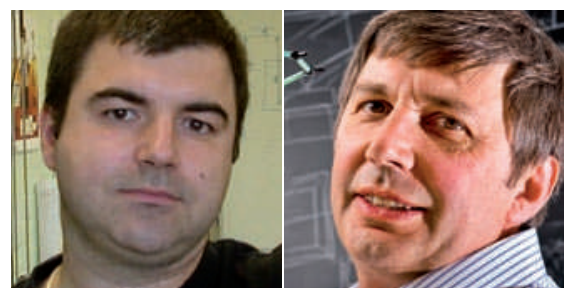

Konstantin Novoselov (left) and Andre Geim: from sticky tape to Nobel prize in just six years.

discovery, researchers realized that graphene was no ordinary material. Electrons travelling through the sheets display unusual quantum behaviours that can be easily studied ${ }^{2,3}$. Graphene's two-dimensional nature, and its atomic structure, also causes electrons to move through it much faster than they do through materials such as silicon.

These properties make graphene a hot prospect for constructing computer chips. Although the sheets themselves do not behave as semiconductors, thin ribbons of graphene do. The ribbons' properties are not ideal for electronics, but advocates believe that graphene's speedy electrons and potential affordability could allow it to one day supplant silicon. A nearer-term use may be as a transparent, conducting layer in touch screens ${ }^{4}$, or as flexible displays.

Graphene has also been teamed with DNA to create a chemical sensor, and can even act as a sponge to clean polluted water. Geim thinks that the material has the potential to be as revolutionary as plastics. "My hope is that graphene and other two-dimensional crystals will change our everyday lives," he says. -

1. Novoselov, K. S. et al. Science 306, 666-669
(2004).
2. Zhang, Y. et al. Nature 438, 201-204 (2005).
3. Novoselov, K. S. et al. Nature 438, 197-200
(2005).
4. Kim, K. S. et al. Nature 457, 706-710 (2009).

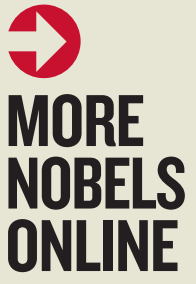

\section{PODCAST}

- Join Nature's podcast team for more discussion of this year's Nobel prizes www.nature.com/nature/podcast - Listen to a 2007 interview with the 'godfather of graphene', Andre Geim go.nature.com/EWfJZA

LATEST NEWS
Catch Nature's
coverage of
the Nobel
Prize in
Chemistry
at go.nature.
com/4BmnDD

\section{FROM THE ARCHIVE}

- Robert Edwards's Commentary on IVF and the history of stem cells go.nature.com/XzoH76

- The future of reproductive medicine go.nature.com/28VL6p - Graphene gets ready for the big time go.nature.com/spRvF5 